\title{
REFLEXÕES SOBRE PROCESSOS COLABORATIVOS DE DESIGN
}

Larisa Paes

Universidade do Estado do Rio de Janeiro

paes.larisa@gmail.com

Zoy Anastassakis

Universidade do Estado do Rio de Janeiro

zoy1974@gmail.com

Resumo: Ao longo dos últimos anos, cada vez mais designers vêm demonstrando uma mudança de atitude perante o público de suas criações. As opiniões dos usuários importam, o projeto é valorizado enquanto processo e a interdisciplinaridade veio aproximar outros campos do ato de pensar projeto em design. O presente artigo, inspirado no trabalho de Richard Buchanan (1995) em que demonstrava a necessidade de se identificar perspectivas retóricas acerca da origem do design, tem como objetivo traçar um paralelo em relação a origem e as possíveis formas de conjugação em torno de processos colaborativos de design em que a experiência do projeto é compartilhada entre profissionais da área (designers) e o público. Com esta finalidade, são elaborados e apresentados esquemas que investigam as raízes e os modos de atuação das seguintes abordagens: design participativo, design centrado no usuário, codesign/cocriação e design anthropology.

Palavras-chave: Design participativo, design centrado no usuário, codesign, cocriação, design anthropology.

\begin{abstract}
Over the past few years, more and more designers are showing a change of attitude towards the public of their creations. Users's view matters, the project is valued as a whole process and the interdisciplinary approaches brought together many other study fields to reckon about the act of designing things in design. This article is inspired on the work of Richard Buchanan (1995) which demonstrated the need to identify rhetorical perspectives about the origin of design, and it aims to draw a parallel with respect to the origin and the possible forms of configuration around collaborative process of design which the experience of designing is shared among professionals (designers) and public. For this propose, some schemes were elaborated and presented to investigate the roots and the practice modes of the following approaches: participatory design, user centered design, codesign / co-creation, design anthropology.
\end{abstract}


Keywords: Participatory design, user-centered design, codesign, cocreation, design anthropology.

\section{INTRODUÇÃO}

As Revoluções Industriais trouxeram o advento de um mundo cada vez mais globalizado, onde as sociedades têm passado por transformações que demandam uma releitura contínua acerca dos modos de produção e do uso de objetos comuns a todos nós. Este fato é especialmente importante para o campo do design, visto o papel que tem exercido ao longo dos anos projetando e instrumentalizando a vida artificial.

Neste cenário, convêm ter em mente que o design é uma disciplina da invenção, e por isso sempre se diferiu das ciências da natureza, onde um objeto de estudo está definido e a sua investigação ocorre com o objetivo da descoberta. No design, o objeto de estudo não é fixo, e a pesquisa pode seguir caminhos exploratórios. Tal inexatidão caracteriza o design como uma disciplina que se preocupa com assuntos que admitem resoluções alternativas, sendo que a natureza essencial do design exige que tanto o processo como os resultados estejam abertos para debate e discordância. (BUCHANAN, 1995: 24 , 25) Sendo assim, em um mundo cada vez mais conectado, onde as sociedades são heterogêneas e as vozes são múltiplas, faz sentido que o campo do design também se ocupe de pensar caminhos mais coletivos e colaborativos para se "fazer design" junto ao público.

Este artigo apresenta um exercício de reflexão sobre processos colaborativos de design, e teve como inspiração o trabalho "Retórica, Humanismo e Design" (1995) de Richard Buchanan. Em relação a sua estrutura, inicialmente é abordado por meio dos esquemas de Buchanan como a forma de observar pode caracterizar e definir o design. Em uma segunda etapa, é elaborado um esquema com as origens de algumas das modalidades mais conhecidas de processos colaborativos de design, sendo: design participativo, design centrado no usuário, codesign / cocriação e design anthropology. Desta forma, ao observar a trajetória histórica e o contexto em que se inseriu cada um destes processos, foi levantada a questão do que realmente os difere entre si no tocante aos modos como se relacionam com o público. Finalmente, é realizada a criação de um novo esquema com a intenção de investigar possíveis perspectivas retóricas, bem como vantagens e desvantagens, de cada um dos processos colaborativos de design em que a experiência de projeto é compartilhada com o público.

\section{DESENVOLVIMENTO}

\subsection{As origens e a retórica do design}

No texto "Retórica, Humanismo e Design" (1995), Richard Buchanan constrói seu argumento acerca da concepção de uma disciplina humanista de design por meio da história, da filosofia e da teoria. A partir desta perspectiva, a teoria e a história do design deveriam equilibrar qualquer discussão sobre a concepção do produto de design, e tudo o que envolve o contexto histórico ser considerado.

Recorrendo a um jogo de espelhos ou simplesmente uma matriz de intenções, Buchanan remonta quatro possíveis origens do design diversas entre si. Os conceitos 
apresentados pelo autor na Figura 1 denotam uma disparidade ampla acerca do assunto.

\section{Creation of the Universe}

Industrial Revolution

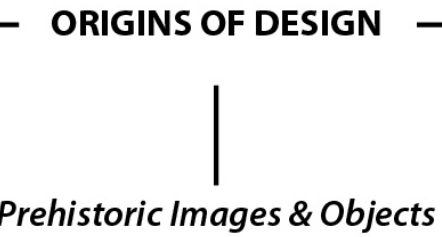

Figura 1 - Esquema das origens do design.

Fonte: Adaptado de: BUCHANAN, 1995, p. 28.

Através do esquema da Figura 1, o autor demonstra que o modo como um escritor identifica as origens do design se conecta também a outros fatores relacionados à natureza humana, às condições sociais, aos mitos culturais, e assim sucessivamente. Tais fatores são pontos retóricos de cada origem, os quais indicam perspectivas muito mais amplas.

Tendo isto em mente, Buchanan apresenta outro esquema (representado na Figura 2) em que destaca a retórica perspectiva que emerge sob cada uma destas origens:

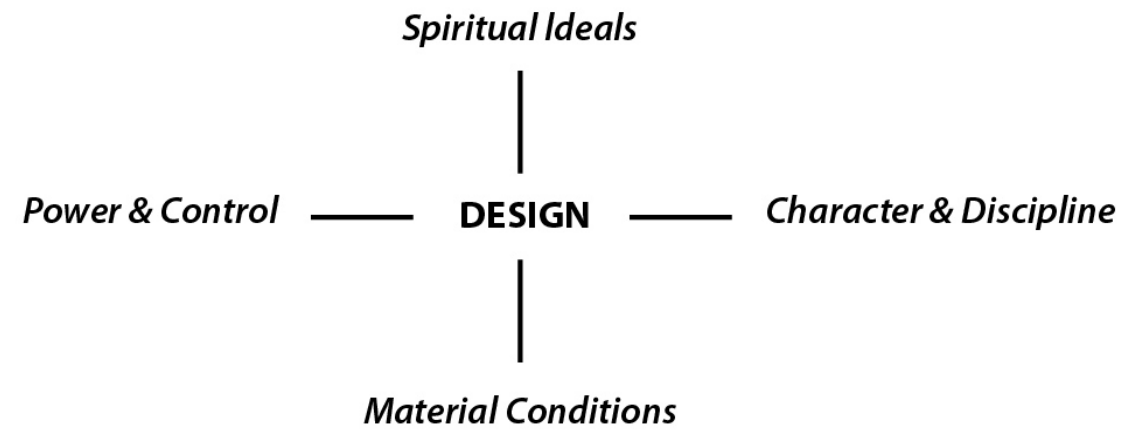

Figura 2 - Esquema dos lugares comuns à prática e teoria do design.

Fonte: Adaptado de: BUCHANAN, 1995, p. 29.

Desta maneira, o grande trunfo da matriz é justamente o convite que o autor faz ao leitor para que observe cada origem indicada através de suas perspectivas distintas e complementares ao entendimento do design como ação intelectual. Ao selecionar apenas uma das origens ignorando a contextualização com as outras, alterase consideravelmente a percepção acerca da natureza do design.

Quando se fala em design a partir da criação do universo é colocada em pauta uma relação dialética com a natureza. Neste modelo, o mundo natural é representado como um ideal de criação ao qual todos os designers devem se esforçar para imitar - é quando o projeto é sempre re-design da natureza. A retórica desta origem repousa nos 
ideais espirituais da Antiguidade e, embora possa parecer apenas um traço do passado, exerce influência ainda nos dias atuais quando embates em torno da teoria de um chamado "Design Inteligente" ainda são presenciados.

Por outro lado, existe também uma vertente que aponta a origem do design a partir das imagens e objetos pré-históricos produzidos pelos homens primitivos. Através do vestígio de seus artefatos e culturas se estabelece uma perspectiva retórica em torno das condições materiais do homem como causa e efeito para com o ato de projetar instrumentos (ou "fazer design").

Tomando por base a origem do design por meio da Revolução Industrial, dialoga-se diretamente com um design que se caracteriza por estar a serviço dos meios de produção e de uma sociedade tecnológica de cultura industrial. Por meio de uma retórica de poder e controle, o design se torna ferramenta essencial de um modelo de consumo estabelecido através da produção seriada de objetos, e que se expande no pós-guerra mundial. Ainda que nos Estados Unidos, nos países da Europa e na América Latina o design desponte e se desdobre de diferentes maneiras ao longo deste período, para esta perspectiva, o processo de "making" (fazer design) se estabelece por meio da configuração de objetos e sistemas em larga escala para o mundo artificial.

Outra origem para o design destacada na matriz de Buchanan, é a formulação de disciplinas (pensamento científico) em torno da ação intelectual do design nos princípios do século XX. Por esta ser uma perspectiva em que a educação é o ponto central do surgimento do design, ela demonstra uma retórica que dialoga com conceitos, características e metodologias necessárias para se estabelecer uma disciplina de design.

Se o design atualmente se apresenta multifacetado pela confusão entre produtos, métodos e objetivos é recomendável averiguar as janelas que o circundam antes de tomar para si uma visão única. Sendo assim, e reconhecendo a dimensão inerentemente retórica que todo o pensamento em design carrega, Buchanan demonstra que é justamente a forma de observar que caracteriza e define o design.

\subsection{As concepções e os formatos de processos colaborativos de design}

A qualidade percebida por Buchanan em torno da observação do historicismo e da perspectiva retórica presente em cada origem do design certamente proporcionou ao longo dos anos novos meios para explorações no campo. Na contemporaneidade, as opiniões do público passaram a ter mais força, pois a agilidade na troca de informações entre as pessoas é cada vez maior. Desta forma, gradualmente mais e mais designers vêm demonstrando uma mudança de atitude perante o público de suas criações.

Se o design é parte de uma disciplina da invenção onde o objeto de estudo nem sempre está bem posto (Buchanan, 1995:24, 25), alguns profissionais já se deram conta disto e hoje abraçam a inexatidão deste objeto de estudo como forma de experimentação e exploração abrindo espaço para a participação de diversos atores no processo de design. Através de processos exploratórios, participativos e 
interdisciplinares, formas mais colaborativas de "fazer design" vêm se configurando e se consolidando.

Resgatando o esquema "Origens do design" proposto por Buchanan (Figura 1), neste trabalho se propõe a criação de um esquema paralelo ao do autor, no qual as possíveis origens de processos colaborativos de design em que a experiência de projeto é compartilhada com o público é investigada. Com este objetivo, foi elaborado o esquema abaixo representado pela Figura 3:

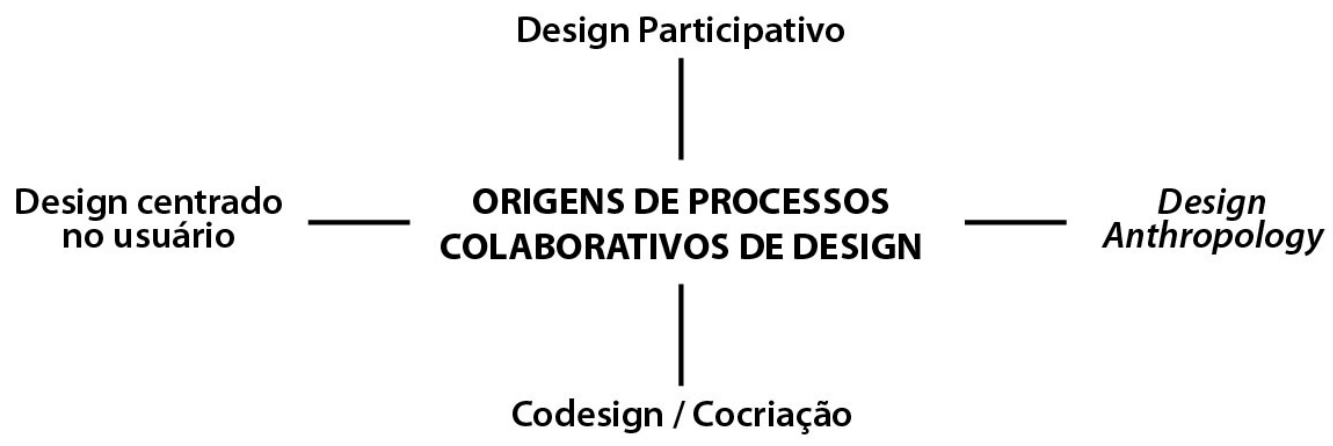

Figura 3 -Esquema das origens de processos colaborativos de design.

Fonte: Elaborado pela autora, com base na pesquisa realizada.

Desta maneira, pretende-se justamente observar estas práticas aparentemente tão similares entre si para, então, refletir sobre os modos como suas perspectivas retóricas caracterizam e definem o design realizado por designers junto ao público.

\subsection{Os diferentes processos colaborativos de design em que a experiência de projeto é compartilhada com o público}

\subsubsection{Design Participativo}

O design participativo (Participatory Design) é uma referência central acerca dos processos de design que envolvem o público. Iniciou-se na Escandinávia dos anos 70 através da participação ativa de usuários (trabalhadores) na elaboração de sistemas de trabalho. Para compreender a sua origem é essencial observar como se deu o processo de industrialização nestes países nórdicos.

Entre o final do século XIX e início do século XX, o design escandinavo caracterizava-se pela forte influência da tradição do artesanato e pelo uso eficiente de recursos naturais limitados. Enquanto nestes países (Noruega, Dinamarca e Suécia) o processo de industrialização tardou mais a se estabelecer do que nos Estados Unidos e outros países da Europa, as teorias sociais de John Ruskin, William Morris e do Movimento Arts\&Crafts se espalharam rapidamente pela Escandinávia e Finlândia. Mais ainda, em 1845, foi criada a Sociedade Sueca de Desenho Industrial, como forma de defender e sustentar elevados padrões em várias profissões relacionadas ao artesanato (EYPÓRSDÓTTIR, 2011). A partir da iniciativa do movimento Arts\&Crafts em integrar os processos derivados do artesanato com a produção comercial e, justamente levando em conta a criação de diversas instituições e escolas em prol de preservar a tradição do artesanato após a 2a Guerra Mundial, torna-se mais clara a compreensão de como se consolidou o modelo fino-escandinavo de design. 
Foi também dentro deste contexto caracterizado por um foco altamente político que os sindicatos de trabalhadores na Escandinávia reagiram contra a implementação de sistemas de automação estabelecidos pelos seus superiores em detrimento da tradição do operador-artesão. Estes sindicatos e trabalhadores reagiram, pois compreenderam que a tecnologia não é neutra e possui um caráter político de poder e controle fortemente atrelado. Nesse sentido, é interessante perceber que os direitos conquistados pelos trabalhadores escandinavos naquela época estabeleceram moldes para a sociedade atual destes países.

\footnotetext{
"Na Escandinávia, os trabalhadores têm o direito de influenciar a mudança técnica ainda em sua fase de desenvolvimento, o que lhes foi garantido através de suas lutas sindicais. Na Suécia, por exemplo, desde 1977 a lei garante aos trabalhadores o direito de co-determinação, o que foi conseguido através das lutas sindicais e, também, do apoio parlamentar." (OLIVEIRA, G.,1991)
}

Desta forma, o design participativo se desenvolveu como uma tradição em que o design acontece com o usuário, tratando o mesmo como um parceiro. No contexto dos países nórdicos, experimentos e métodos tinham como objetivo aumentar o valor da produção e engajar os trabalhadores no desenvolvimento de novos sistemas para o local de trabalho. Sendo assim, esta abordagem reúne as habilidades do designer e o conhecimento tácito das pessoas que serão impactadas pelas mudanças projetadas, de modo que não somente o projeto é construído com base nas experiências do público como também lhes é fornecido recursos que os capacitam a agir em seus problemas atuais. (Bødker apud Sanders \& Stappers, 1996)

\subsubsection{O design centrado na experiência do usuário}

Durante os anos 80 , em meio ao movimento de popularização da computação pessoal nos Estados Unidos, a expressão "design centrado no usuário" surgiu nos trabalhos do teórico Donald Norman (1986), e credita-se a ele o pioneirismo no uso do termo.

Se antes as pesquisas em inteligência artificial estavam focadas em minimizar as interfaces de usuário para evitar o chamado "erro humano", neste momento a responsabilidade por tais erros tornou-se das próprias interfaces dos sistemas computacionais que, por vezes muito confusas, induziam ao erro. Desta forma, pesquisadores da cognição humana se esforçaram para formular uma abordagem menos formal de modo que o usuário seria essencial ao projeto, ao invés de um fator de risco.

Os processos de design centrado no usuário obviamente são focados nas necessidades do usuário. Realiza-se tanto atividades de análise quanto de interpretação de critérios, aonde é dado andamento à testes e avaliações iterativamente (RITTER et al., 2014). Desse modo, percebe-se que o conceito fundamental desta abordagem reside na diferença do modelo mental do designer e do usuário. $\mathrm{O}$ usuário é convidado a interagir com o sistema para construir e demonstrar um modelo mental à partir de sua experiência prévia, ao passo que este modelo pode ser completamente diferente daquele construído pelo designer. Através de diversos métodos que envolvem a observação e testes, pretende-se aproximar o modelo do designer ao do usuário, de modo que no modelo projetado a interação com o sistema ocorra de maneira intuitiva. É importante ressaltar que nesta tradição o design é 
pensado para o usuário e, embora este mesmo usuário esteja no centro do projeto, ainda assim ele não participa das tomadas de decisão.

\subsubsection{Codesign / cocriação}

Atualmente existe muita confusão em torno dos termos codesign e cocriação. Enquanto alguns profissionais tratam o codesign como um sinônimo da abordagem de design participativo, a cocriação é comumente relacionada à ferramentas e paradigmas de marketing.

Sanders \& Stappers (2008) afirmam que o codesign como é praticado e discutido hoje se desdobra de diferentes maneiras dependendo da experiência e da forma de pensar de seus praticantes. Para eles, codesign indica a criatividade coletiva aplicada através de todo um processo de design. Codesign, para os autores, é uma instância específica da cocriação. Sanders \& Stappers ressaltam ainda que os proponentes mais conhecidos do codesign vieram de áreas como a administração e o marketing ao invés do design, como é o caso de C. K. Prahalad e Venkat Ramaswamy, autores do livro "The Future of Competition: Co-Creating Unique Value with Customers". A partir da perspectiva destes autores, a cocriação é o desenvolvimento, por stakeholders diversos, de experiências de geração de valor que sejam benéficas para todos os envolvidos, por meio de plataformas de engajamento entre consumidores e empresa (PRAHALAD \& RAMASWAMY, 2004).

Por outro lado, a cocriação e o codesign relatados a partir da perspectiva de profissionais do design tende a adquirir um teor mais exploratório do que mercadológico:

\footnotetext{
"Codesign, também conhecido como design colaborativo, é uma forma de pesquisa em design que envolve os usuários finais no processo de criação de um produto, plataforma, publicação ou ambiente. Os designers de hoje em dia aprenderam que os usuários são especialistas em seus próprios domínios. Muitos designers atualmente veem a si próprios não como controladores do resultado final, mas sim como desencadeadores de um processo que envolve ativamente um público." (LUPTON, E., 2013, p. 96)
}

Dentro deste mesmo contexto, o programa de mestrado em codesign na Dinamarca oferecido pela Royal Danish Academy of Fine Arts, School of Design, esclarece em seu website que o codesign é uma investigação crítica de novas possibilidades, onde diversos parceiros (e não usuários) estão ativamente envolvidos em diálogos concretos sobre o que constitui futuros atraentes a partir de diferentes pontos de vista. Além disso, o programa ainda ressalta que o codesign se baseia nas tradições de design centrado no usuário, design participativo, design crítico e etnografia.

No tocante à aproximação do codesign ao design participativo e às demais abordagens citadas, Binder et al. (2015) esclarecem que, durante as últimas décadas, o foco tem mudado do ambiente de trabalho e do trabalhador para o espaço público e o cidadão. Codesign hoje vai além do local de trabalho, das relações laborais e dos quadros institucionais para se envolver em e com diversos públicos emergentes, como 
um ator em "experimentos democráticos de design"1, e deve voltar a encontrar maneiras de se engajar naqueles marginalizados por infraestruturas hegemônicas. Mais ainda, percebe-se o "computador" não mais como uma tecnologia de automação de sistemas, mas sim como um ator no processo de reconfiguração do espaço público e do engajamento cidadão por meio da internet e das mídias sociais, abrindo espaço tanto para novos públicos, quanto para questões de interesse coletivo e controvérsias possíveis.

De todas as maneiras, as noções de cocriação e codesign caminham cada vez mais rumo à práticas criativas coletivas e colaborativas. Ao invés de denotarem uma motivação permeada apenas por processos políticos, acadêmicos ou tecnológicos, evidenciam também a ascensão da cultura do faça-você-mesmo (LUPTON, 2013).

\subsubsection{Design Anthropology}

Pouco antes da virada do milênio, um campo híbrido e emergente formado à partir da aproximação do design com a antropologia se configurou. O Design Anthropology, tal como é reconhecido hoje, teve suas raízes na popularização da prática da etnografia em projetos de design centrado no usuário. Ainda que o design e as ciências sociais tenham começado a dialogar na década de 1970, foi através de um projeto desenvolvido em 1980 pela Xerox no Centro de Pesquisa de Palo Alto que percebeu-se efetivamente uma aproximação interdisciplinar dessas duas grandes áreas (GUNN \& DONOVAN, 2012, p. 22). Nesse sentido, considerando que dentro da lógica capitalista o design sempre foi visto como uma potencial ferramenta de vendas, não é estranho que a inclusão da etnografia como parte da pesquisa para desenvolvimento de projeto também tenha surgido com o objetivo final de gerar lucro. Atualmente, porém, a proposta de junção destes campos pretende mais do simplesmente instrumentalizar o design com ferramentas de antropologia ou viceversa.

Quando se fala em Design Anthropology, o que está em jogo "não é nem uma antropologia do design, nem um design antropológico, mas, sim, o exercício de uma experimentação interdisciplinar que busca operar a partir da conjugação entre as duas disciplinas." (ANASTASSAKIS \& KUSCHNIR, 2014, p. 5)

Desta forma, Gunn \& Donovan (2012) ressaltam que a prática do Design Anthropology busca instigar diferentes formas de "fazer design" em situações emergentes e em diferentes escalas, comprometendo-se com pessoas e lugares em que o problema nem sempre está bem posto, e saindo da concepção de um design problem-oriented.

\section{CONCLUSÃO}

Enquanto a discussão apresentada no desenvolvimento deste trabalho descreve as motivações históricas nas origens dos processos colaborativos apresentados, a partir destas informações emerge o questionamento acerca de qual é

\footnotetext{
1 "We think of codesign as drawing things together. We see things as matters that concern us. Both as a 'laboratory' where this concern can be explored, and as a 'parliament' where what is good and what is bad can be negotiated. To capture this intertwining of exploring and negotiating we call what is drawn together a democratic design experiment." (Binder in Aagaard et al., 2015: 8)
} 
a perspectiva retórica por trás de cada abordagem supracitada. Por que escolher uma abordagem em detrimento de outra? Ou ainda, qual é a vantagem de se perceber a existência e os modos de mais de uma modalidade de processo colaborativo de design?

Por estes questionamentos, desenvolveu-se um novo esquema (Figura 4) onde são apresentadas possíveis perspectivas retóricas de cada abordagem citada:

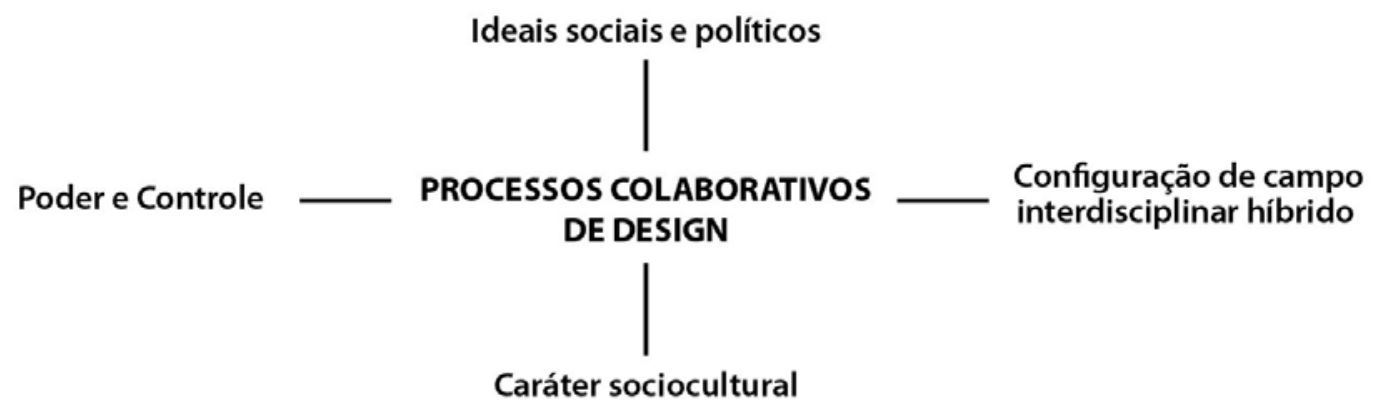

Figura 4 - Esquema dos processos colaborativos de design.

Fonte: Elaborado pela autora, com base na pesquisa realizada.

Para o design participativo, ideais sociais e políticos estão em cena. Nesta tradição é fundamental que a apropriação dos sistemas ocorra por meio da participação do público que, uma vez conhecendo como foram configurados, têm mais chances de dominar as possibilidades de uso e modifica-los sempre quando necessário. Desta forma, a participação acontece de maneira bastante ativa, porém, para que isso possa ocorrer, é necessário que o público esteja consciente dos processos políticos em jogo.

A modalidade de design centrado no usuário está relacionada à perspectiva de poder e controle. Não existe uma intenção de emancipar o público (nesta tradição nomeado "usuário"), mas sim de sistematizar e de certa forma hegemonizar a apropriação tecnológica. Ainda assim, a abordagem de design centrado no usuário é bastante valorizada em projetos do setor privado, onde o foco está mais no produto final a ser desenvolvido e nas vendas do que na geração de autonomia para o público.

Em relação aos projetos de codesign e cocriação reside o caráter sociocultural. Nesta tradição, o design não atua para estabelecer parâmetros, mas desencadeia processos para um público se formar e para um tipo de engajamento cívico ser despertado. Por um lado, evidencia-se uma clara aproximação às tradições citadas e também à assimilação do sentimento de "faça-você-mesmo", onde as pessoas se sentem empoderadas pela simples expressão criativa e coletiva de suas ideias catalisadas em um processo de design colaborativo. Por outro lado, esse tipo de abordagem demanda a constante negociação e re-negociação de objetivos múltiplos entre o público, parceiros e designers; necessita tempo para a construção de relações baseadas na confiança entre os atores; além de que todo esse processo desenvolvido não oferece garantias acerca do que se resulta ao fim do projeto.

Para o design anthropology, o que está em jogo é a apropriação de um campo interdisciplinar híbrido fundamentado no que são e no que podem ser as práticas e modo de vida das pessoas. Se, por um lado representa a aproximação de duas áreas de 
conhecimento em prol da conjugação de projetos mais significativos para o público, por outro lado, também existe ainda uma fragilidade para os profissionais em transitar entre essas áreas sem subjugar uma à outra.

Finalmente, conclui-se que o processos colaborativos de design têm se apresentado em mais de uma modalidade ao longo dos anos, cada qual com seus diversos desdobramentos (políticos, tecnológicos, acadêmicos, culturais), e com suas vantagens e desvantagens em relação ao modo de atuação junto aos atores. Conforme foi demonstrado por Buchanan em seus esquemas e argumentado durante todo este trabalho, é essencial que haja consciência de que sempre existe mais de uma perspectiva no tocante aos processos de design, pois a partir desta percepção se caracterizam e se definem as formas de praticar design junto ao público.

\section{REFERÊNCIAS}

AAGAARD, Isabel et. al. Democratic design experiments: drawing things together with codesign. Copenhagen: The Royal Danish Academy of fine Arts, 2015.

ANASTASSAKIS, Zoy; KUSCHNIR, Elisa. Trazendo o design de volta à vida: considerações antropologicamente informadas sobre as implicações sociais do design. Em: Guilherme de Cunha Lima; Lígia Medeiros. (Org.). Textos selecionados de design 4. 1ed.Rio de Janeiro: PPDESDI/UERJ, v. 4, p. 137-141, 2013.

BINDER, Thomas; BRANDT, Eva; EHN, Pelle; HALSE, Joachim. Democratic design experiments: between parliament and laboratory. Em: CoDesign, Vol. 11, No. 3-4, 01.10.2015, p. 152-165. Journal article. 2015.

BUCHANAN, Richard. Rethoric, Humanism and Design. Em: BUCHANAN, Richard; MARGOLIN, Victor (Eds.). Discovering Design. Explorations in Design Studies. Chicago and London: The University of Chicago Press, 1995, p. 23-66.

CODESIGN MASTER'S PROGRAM. Em: Site da Royal Danish Academy of Fine Arts, School of Design. Disponível na internet por http em: <http://ma-codesign.org/>. Acesso em 20 jul. 2015.

EYPÓRSDÓTTIR, Katrín. The Story Of Scandinavian Design: Combining Function and Aesthetics. Smashing Magazine, publicado em 13/07/2011. Disponível na internet por http em: <http://www.smashingmagazine.com/2011/06/13/the-story-of-scandinaviandesign-combining-function-and-aesthetics/>. Acesso em 09 jul. 2015.

GUNN, W. \& DONOVAN, J (editors). Design and Anthropology (Anthropological studies of creativity and perception). Ashgate Publishing Company, 2012.

GUNN, Wendy; OTTO, Ton; SMITH, Rachel Charlotte (editors). Design Anthropology: Theory and Practice. Bloomsbury Academic, 2013.

OLIVEIRA, Gabriela de. Democratização das relações de trabalho na empresa. Revista de Administração de Empresas, volume 31, no 4, publicado em São Paulo out./dez. 1991. Disponível em: <http://www.scielo.br/scielo.php?script=sci_arttext\&pid=S003475901991000400009\&lng=pt\&nrm=iso\&tlng=en> Acessado em: 09 jul. 2015. 
PRAHALAD, C. K. \& RAMASWAMY, Venkat. Co-creation experiences: the next practice in value creation. Wiley Periodicals, Inc. and Direct Marketing Educational Foundation, Inc. Journal of interactive marketing volume 18 / number 3 / summer 2004.

RITTER, Frank E.; BAXTER; GORDON D.; CHURCHILL, Elizabeth F. Foundations for Designing User-Centered Systems - What System Designers Need to Know about People, Springer-Verlag London, 2014.

SANDERS, Elizabeth B. N. \& STAPPERS, Pieter Jan. Co-creation and the new landscapes of design. Preprint of an article submitted for consideration in CoDesign, Taylor \& Francis, March 2008. 